\title{
PENGEMBANGAN PERANGKAT LUNAK PERANCANGAN LAPIS ULANG PERKERASAN LENTUR BERDASARKAN MANUAL BINA MARGA 2017
}

\author{
Berlian Kushari $\left.{ }^{1, *}\right)$ dan Nur Robbi Hidaya ${ }^{2}$ \\ ${ }^{1, *)}$ Laboratorium Jalan Raya, Jurusan Teknik Sipil, Universitas Islam Indonesia, Yogyakarta \\ Email: bkushari@uii.ac.id \\ ${ }^{2}$ Program Studi Teknik Sipil, Universitas Islam Indonesia, Yogyakarta \\ Email: nurrobbihidayaa@gmail.com
}

\begin{abstract}
The Benkelman Beam method is used to design overlay thickness on a flexible pavement based on its maximum rebound deflection representing its structural capacity. This method has been adopted in the 2017 Bina Marga Design Manual applicable for Indonesian road design since June 2017. This research was aimed to develop a tool that can facilitate rebound deflection data analysis and overlay thickness design based on the overlay design curves adopted in the Bina Marga guide. Visual Basic 6.0 was used as the environment for the development. In addition to the standard curves, the tool added four intermediate curves corresponding to the design load of $7.5 \times 10^{6}, 3.5 \times 10^{6}, 1.5 \times 10^{6}$, and $0.75 \times 10^{6}$ ESALs to enable more economical designs. Furthermore, a manual overlay procedure was conducted using overlay data from Sampaan - Singosaren, Kowangan - Maron, and Imogiri Barat road sections to validate the usability of the developed tool. The validation showed an acceptable difference of less than $2 \%$ between results obtained from the software and the manual calculations.
\end{abstract}

Keywords: Benkelman Beam, 2017 Bina Marga Design Manual, Visual Basic, overlay design curves

\section{PENDAHULUAN}

Kondisi struktural perkerasan lentur yang telah menurun sering kali ditandai dengan munculnya berbagai macam kerusakan, seperti retak kulit buaya, alur, lubang dan pelepasan butiran agregat. Upaya pemeliharaan dan rehabilitasi perlu dilakukan secara terencana, tepat waktu, serta tepat sasaran untuk memelihara aset jalan yang merupakan investasi milik publik agar dapat mencapai umur rencananya.

Salah satu upaya untuk memperbaiki kondisi struktural perkerasan lentur adalah dengan pelapisan ulang (overlay). Kebutuhan tebal lapis ulang pada perkerasan lentur dengan beban rencana di bawah $10 \times 10^{6}$ ESAL dapat dihitung menggunakan metode Benkelman Beam. Untuk beban rencana di atas nilai tersebut disarankan menggunakan pendekatan mekanistik empiris (TRB, 2004 dan Bina Marga, 2017).

100

*) email korespondensi
Metode Benkelman Beam dikembangkan oleh Western Association of State Highway Organizations (WASHO) Amerika Serikat pada tahun 1952 (WASHO, 1954). Dengan metode ini, tebal lapis ulang pada perkerasan lentur dapat diperhitungkan dari nilai lendutan balik (rebound deflection) representatif hasil pengukuran lapangan menggunakan alat balok Benkelman. Lendutan balik pada perkerasan tersebut terjadi sebagai akibat dari pembebanan truk seberat $80 \mathrm{kN}$ dengan sumbu tunggal roda ganda yang bertekanan angin antara 480 hingga $550 \mathrm{kPa}$. Sebagai suatu uji standar, metode ini dibakukan pada standar AASHTO T 256 dan ASTM D 4695. Di Indonesia metode ini diadopsi pada standar SNI 032416-1991 (BSN, 2011) pedoman Ditjen Bina Marga Nomor Pd-T-05-2005-B, dan terakhir kembali diadopsi dalam Manual Disain Perencanaan Jalan (MDPJ) Bina Marga 2017 dengan modifikasi. 
Penggunaan metode Benkelman Beam dalam evaluasi kondisi struktural perkerasan lentur telah banyak dilakukan di Indonesia, baik dalam konteks penelitian maupun kegiatan rutin pemeliharaan jalan. Sebagai contoh, Susilo (2017) melakukan evaluasi kondisi struktural pada perkerasan Jalan Imogiri Barat, Daerah Istimewa Yogyakarta. Selain itu, Prakoso (2018) melakukan penelitian pada ruas Jalan Kowangan - Maron menggunakan metode Pavement Condition Index (PCI) dan metode Lendutan Balik berdasarkan Pd-T-05-2005-B.

Beberapa perangkat lunak juga telah dikembangkan untuk membantu perhitungan perencanaan tebal perkerasan dan lapis ulang. Saltan, Tigdemir, dan Karasahin (2002), telah mengembangkan aplikasi perhitungan tebal perkerasan menggunakan Jaringan Syaraf Tiruan (Artificial Neural Network, ANN). Selain itu, Abo-Hashema (2009) juga menggunakan ANN untuk mengembangkan aplikasi perancangan tebal lapis ulang. Kedua contoh di atas dikembangkan berdasarkan pendekatan mekanistik-empiris.

Di Indonesia, pendekatan empiris masih digunakan untuk perencanaan lapis ulang dengan beban rencana di bawah $10 \times 10^{6}$ ESAL berdasarkan metode Benkelman Beam. Beberapa peneliti telah mengembangkan pula perangkat bantu perhitungan dalam konteks ini. Gusmalawati (2016), misalnya, mengembangkan perangkat lunak dengan aplikasi VBA-Excel berdasarkan standar Pd T-05-2005-B. Validasi hasil perhitungan perangkat lunak dalam penelitian tersebut dilakukan dengan perhitungan manual berdasarkan data Jalan Bangunjiwo-Bibis dan Jalan Karangjati sepanjang $2 \mathrm{~km}$. Perbedaan hasil perhitungan menggunakan perangkat lunak dengan hasil perhitungan manual sebesar $0,3 \%$.

Pada studi ini, perangkat lunak perancangan tebal lapis tambahan (overlay) metode Benkelman Beam dikembangkan kembali dengan mengacu pada kurva desain Bina Marga 2017. Perangkat lunak ini juga menambahkan 4 kurva desain baru pada nomogram yang diinterpolasi dari kurvakurva desain aslinya guna memberikan lebih banyak pilihan tebal perkerasan tambahan dan desain yang lebih ekonomis. Perangkat lunak dikembangkan dengan bahasa Visual Basic 6.0 dan divalidasi dengan perhitungan manual menggunakan data dari ruas Jalan Imogiri Barat (Susilo, 2017), Kowangan - Maron (Prakoso, 2018), dan ruas Sampaan Singosaren.

\section{METODOLOGI}

Prosedur perhitungan yang diadopsi pada perangkat lunak ini mengikuti MDPJ Bina Marga 2017. Kurva-kurva desain tebal lapis tambahan dalam manual tersebut diproduksi kembali secara numeris dengan teknik penyetelan kurva (curve fitting). Setelah itu, dikembangkan 4 (empat) kurva antara dengan teknik interpolasi. Keempat kurva tersebut adalah kurva untuk beban rencana $7,5 \times 10^{6}$, $3,5 \times 10^{6}, 1,5 \times 10^{6}$ dan $0,75 \times 10^{6}$ ESAL. Penambahan kurva-kurva desain ini dilakukan dengan tujuan untuk meningkatkan ketelitian perhitungan tebal lapis tambahan, mengingat selisih tebal lapis yang disarankan dua kurva yang mengapit kurva-kurva tambahan tersebut masih cukup tebal, yaitu sekitar $20 \mathrm{~mm}$. Dengan peningkatan ketelitian, ini maka hasil perhitungan tebal dapat menjadi lebih ekonomis.

\section{Prosedur Perhitungan Overlay}

Menurut MDPJ Bina Marga 2017, prosedur perhitungan kebutuhan tebal lapis tambahan dimulai dengan analisis proyeksi beban lalu lintas yang akan menggunakan perkerasan hingga akhir umur rencana (CESAL). Selanjutnya, dilakukan analisis nilai lendutan balik Benkelman Beam dan penyesuaiannya terhadap faktor musim, serta penentuan tebal lapis sesuai dengan nilai lendutan karakteristik maksimumnya.

\section{Beban Sumbu Standar Kumulatif}

Beban ekivalen sumbu standar kumulatif (CESAL) dihitung sebagai jumlahan kumulatif dari beban sumbu lalulintas yang dikelompokkan menurut jenis kendaraannya, 
yang diperkirakan akan melintas pada lajur rencana (design lane) selama masa umur rencana (design period). Jika $\mathrm{ESA}_{\mathrm{TH} 1}$ adalah kumulatif lintasan sumbu standar ekivalen pada tahun pertama setelah perkerasan direhabilitasi, $\mathrm{LHR}_{\mathrm{JK}}$ adalah lintas harian rata-rata tiap jenis kendaraan niaga (satuan kendaraan/hari), $\mathrm{VDF}_{\mathrm{JK}}$ adalah faktor rusak untuk tiap jenis kendaraan berat, DD faktor distribusi arah, DL faktor distribusi lajur dan $\mathrm{R}$ faktor pengali pertumbuhan lalu lintas kumulatif, maka $\mathrm{ESA}_{\mathrm{TH} 1}$ dapat dihitung dengan Persamaan (1).

$E S A_{T H I}=\left(\Sigma L H R_{J K} \cdot V D F_{J K}\right) \cdot 365 \cdot D D \cdot D L \cdot R(1)$

\section{Kurva Desain Overlay}

MDPJ Bina Marga 2017 menyarankan penentuan tebal lapis tambahan (overlay) dihitung berdasarkan kurva-kurva desain yang dapat dilihat pada Gambar 1. Desain berdasarkan kurva-kurva tersebut dipandang lebih ekonomis untuk kasus di Indonesia daripada menggunakan pedoman terdahulu, baik Pd T-05-2005 maupun versi yang telah dimodifikasi menjadi pedoman interim No.002/P/BM/ 2011. Delapan kurva desain disediakan oleh MDPJ 2017, masing-masing untuk beban rencana $0,1 \times 10^{6}$ hingga $10 \times 10^{6}$ CESAL.

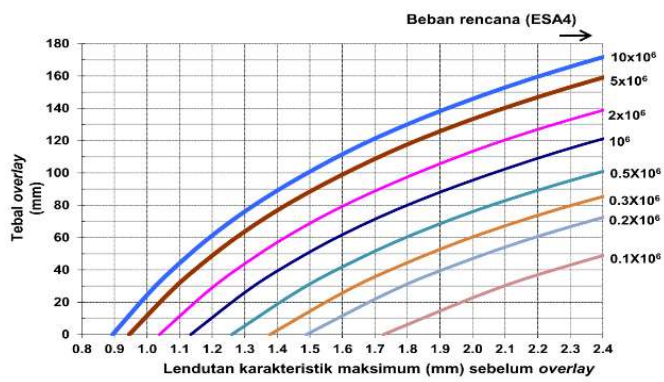

Gambar 1. Kurva desain overlay berdasarkan lendutan balik Benkelman Beam

(Ditjen Bina Marga, 2017)

\section{Teknik Penyetelan Kurva (curve fitting)}

Teknik penyetelan kurva digunakan untuk mereproduksi kurva-kurva desain overlay MDPJ 2017 Bina Marga. Penyetelan kurva bertujuan untuk mencari kurva pendekatan terbaik yang mampu merepresentasikan hubungan antara nilai $x$ dan fungsi $f(x)$
(Sarwidi, 2015). Kualitas kurva dapat diukur dan diekspresikan dengan berbagai cara ukuran penyimpangan atau galat (error). Penentuan galat $(\varepsilon)$, yang digunakan dalam hal ini mengikuti kriteria kuadrat kesalahan terkecil (least square criterion) dapat dilihat ada Persamaan (2).

$$
\varepsilon=\sum_{i=1}^{m}\left(y_{i}-\bar{y}(a)\right)^{2}
$$

Kurva desain MDPJ didekati dengan bentuk persamaan polinomial. Pendekatan polinomial dipilih karena kemampuannya untuk mereproduksi sedekat mungkin kurva desain Bina Marga secara empirik pada batasbatas tertentu, dengan galat yang kecil (di bawah 1\%). Untuk persamaan polinomial berorde $m$ dapat dilihat pada Persamaan (3).

$y=a_{0}+a_{1} x+a_{2} x^{2}+\cdots+a_{m} x^{m}$

Kemudian dapat dihasilkan suatu sistem persamaan yang dapat disusun dalam bentuk perkalian matriks pada Persamaan (4) sehingga nilai-nilai $a_{0}, a_{1}, a_{2}, \ldots, a_{\mathrm{m}}$ dapat ditentukan secara simultan.

$\left[\begin{array}{ccccc}n & \sum x_{i} & \sum x_{i}^{2} & \cdots & \sum x_{i}^{m} \\ \sum x_{i} & \sum x_{i}^{2} & \sum x_{i}^{3} & \cdots & \sum x_{i}^{m+1} \\ \sum x_{i}^{2} & n \sum x_{i}^{3} & n \sum x_{i}^{4} & \cdots & \sum x_{i}^{m+2} \\ \cdots & \cdots & \cdots & \cdots & \cdots \\ \sum x_{i}^{m} & \sum x_{i}^{m+1} & \sum_{i}^{m+2} & \cdots & \sum x_{i}^{m+m}\end{array}\right]\left[\begin{array}{c}a_{0} \\ a_{1} \\ a_{2} \\ \cdots \\ a_{m}\end{array}\right]=\left[\begin{array}{c}\sum y_{i} \\ \sum x_{i} y_{i} \\ \sum x_{i}^{2} y_{i} \\ \cdots \\ \sum x_{i}^{m} y_{i}\end{array}\right](4)$

\section{PENGEMBANGAN SOFTWARE}

\section{Pendekatan Kurva Desain Overlay}

Berdasarkan teknik penyetelan kurva di atas, dihasilkan persamaan-persamaan polinomial pendekatan kurva desain sebagiamana yang terlihat pada Tabel 1 yang akan diimplementasikan dalam perangkat lunak. Adapun kurva antara untuk beban 7,5 x $10^{6}$, $3,5 \times 10^{6}, 1,5 \times 10^{6}$ dan $0,75 \times 10^{6} \mathrm{CESAL}$ ditambahkan dengan teknik interpolasi dari dua kurva yang berdekatan dengan tiap-tiap kurva antara tersebut.

Gambar 2 menyajikan keduabelas kurva disain yang diimplementasikan di dalam perangkat lunak. 
Tabel 1. Persamaan polinomial kurva-kurva desain overlay untuk perangkat lunak

\begin{tabular}{|c|l|c|}
\hline $\begin{array}{c}\text { Beban } \\
\text { Rencana } \\
(\text { ESAL) }\end{array}$ & \multicolumn{1}{|c|}{ Persamaan Polinomial Hasil Penyetelan Kurva } & $\begin{array}{c}\text { Galat } \\
(\varepsilon) \%\end{array}$ \\
\hline $10 \times 10^{6}$ & $\mathrm{y}=-490,000+979,444 \mathrm{x}-663,889 \mathrm{x}^{2}+228,395 \mathrm{x}^{3}-30,86 \mathrm{x}^{4}$ & 0,210 \\
\hline $5 \mathrm{x} 10^{6}$ & $\mathrm{y}=-339,761+548,856 \mathrm{x}-243,869 \mathrm{x}^{2}+50,469 \mathrm{x}^{3}-3,330 \mathrm{x}^{4}$ & 0,260 \\
\hline $2 \mathrm{x} 10^{6}$ & $\mathrm{y}=-493,001+875,449 \mathrm{x}-530,918 \mathrm{x}^{2}+159,341 \mathrm{x}^{3}-18,498 \mathrm{x}^{4}$ & 0,260 \\
\hline $1 \times 10^{6}$ & $\mathrm{y}=-527,994+928,858 \mathrm{x}-591,402 \mathrm{x}^{2}+118,398 \mathrm{x}^{3}-23,486 \mathrm{x}^{4}$ & 0,080 \\
\hline $0,5 \mathrm{x} 10^{6}$ & $\mathrm{y}=-282,774+308,954 \mathrm{x}-67,689 \mathrm{x}^{2}-1,489 \mathrm{x}^{3}+1,560 \mathrm{x}^{4}$ & 0,258 \\
\hline $0,3 \times 10^{6}$ & $\mathrm{y}=-900,863+1636,066 \mathrm{x}-1145,041 \mathrm{x}^{2}+379,789 \mathrm{x}^{3}-48,088 \mathrm{x}^{4}$ & 0,257 \\
\hline $0,2 \mathrm{x} 10^{6}$ & $\mathrm{y}=-259,769+254,174 \mathrm{x}-62,210 \mathrm{x}^{2}+5,793 \mathrm{x}^{3}$ & 0,199 \\
\hline $0,1 \mathrm{x} 10^{6}$ & $\mathrm{y}=-268,118+246,852 \mathrm{x}-66,202 \mathrm{x}^{2}+7,740 \mathrm{x}^{3}$ & 0,124 \\
\hline
\end{tabular}

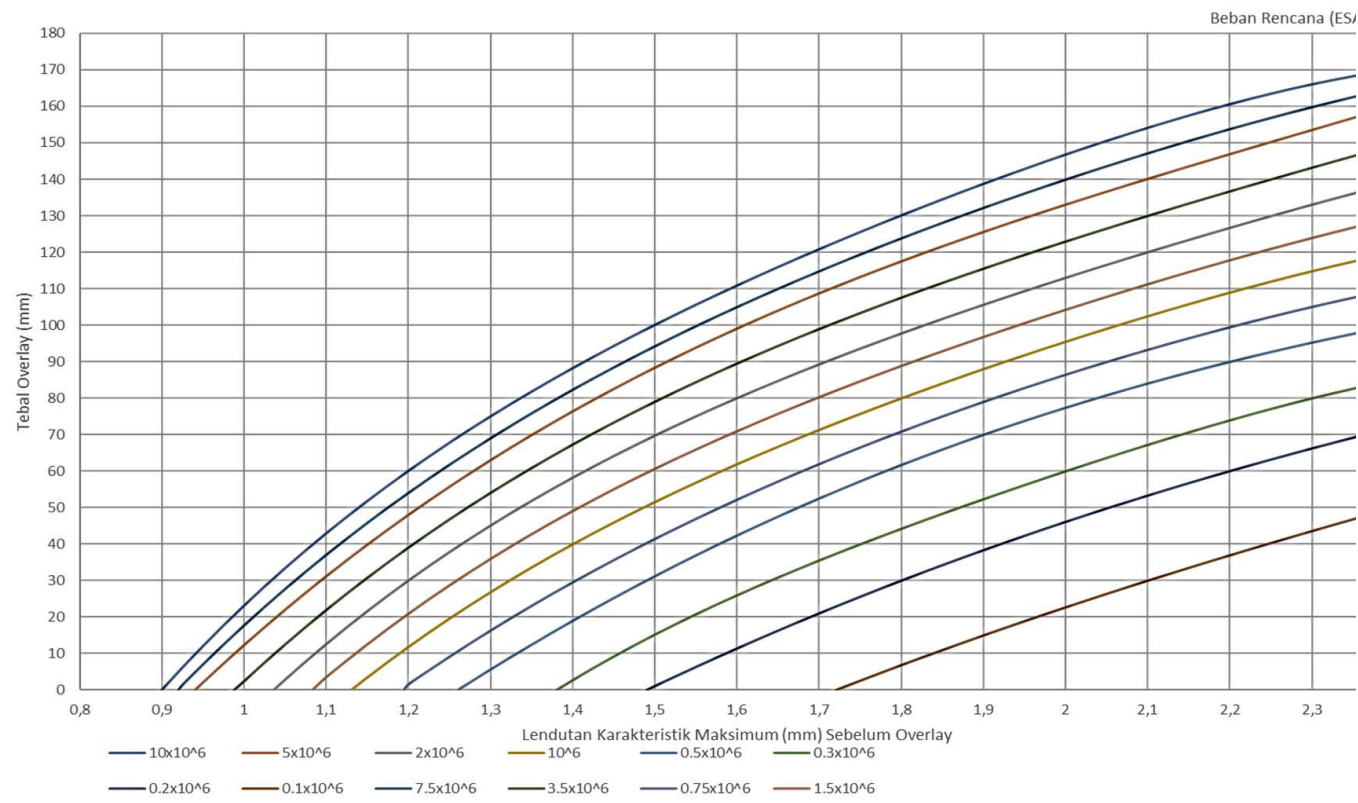

Gambar 2. Kurva desain overlay hasil penyetelan kurva

\section{Fitur dan Tampilan Antarmuka}

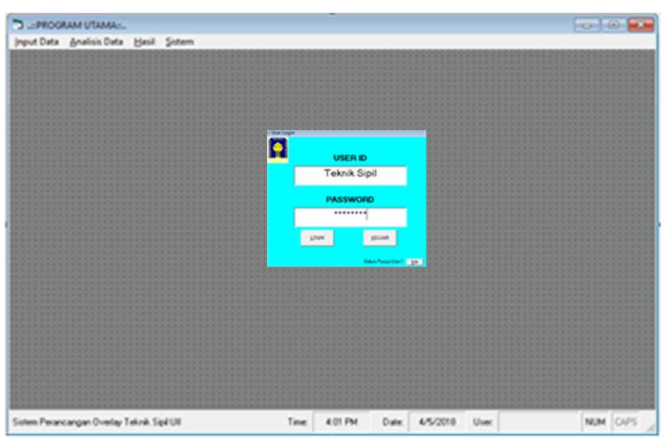

Gambar 3. Tampilan menu utama
Beberapa tampilan hasil desain perangkat lunak dapat dilihat pada Gambar 3 hingga 8. Gambar 3 menyajikan tampilan menu utama yang terdiri dari menu Input Data, Analisis Data, Hasil, dan Sistem. Perangkat lunak ini dapat menangani banyak dokumen dan banyak pengguna (multiple document interface). Oleh karena itu, pengguna perlu membuat akun personal untuk melakukan log-in dengan username dan password unik. 


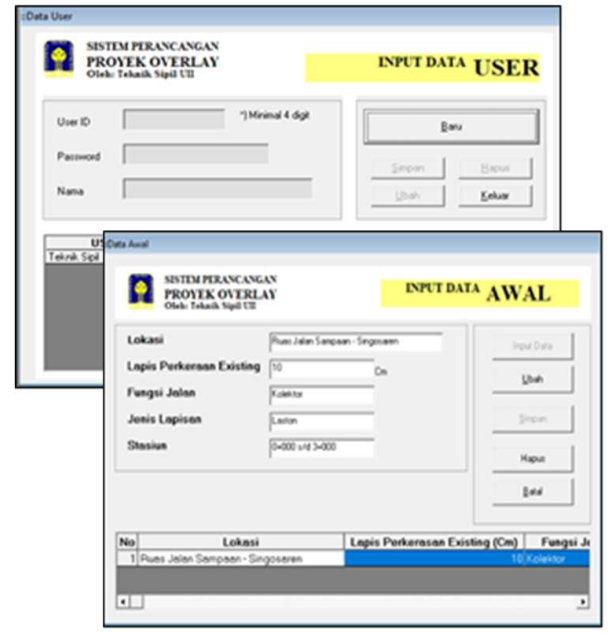

Gambar 4. Tampilan input data pengguna dan data informasi ruas jalan

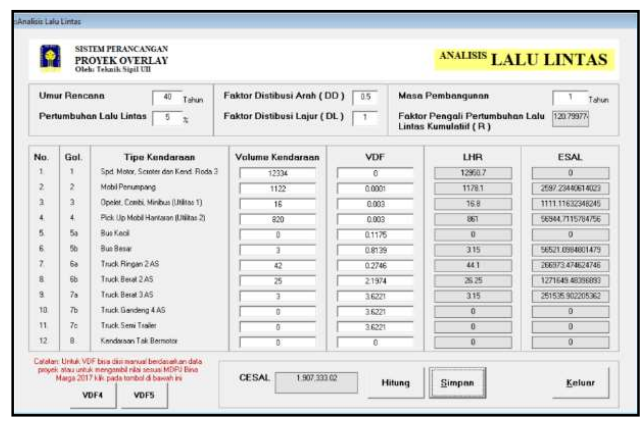

Gambar 5. Menu analisis lalu lintas

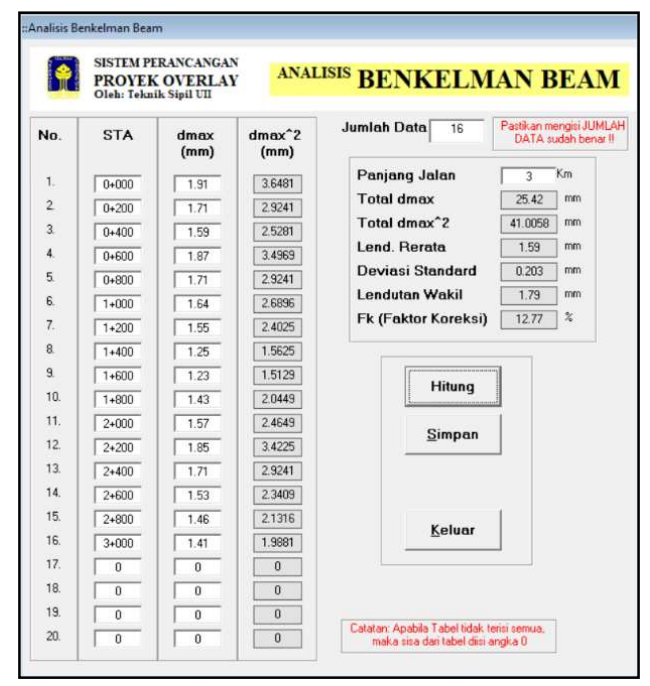

Gambar 6. Menu analisis data lendutan balik dari alat Benkelmen Beam
Gambar 4 menyajikan tampilan input data indentitas pengguna (user) dan informasi tentang ruas jalan. Gambar 5 menyajikan menu analisis lalu lintas. Pada menu ini, nilainilai VDF dapat diisi sesuai dengan data lapangan ataupun mengadopsi nilai yang disarankan oleh MDPJ 2017 Bina Marga. Analisis data Benkelman Beam dilakukan pada menu berikutnya yang ditunjukkan oleh Gambar 6. Pada tahap ini akan dihasilkan keluaran di antaranya lendutan rerata, deviasi standar, lendutan representatif (wakil), dan faktor keseragaman $\left(f_{k}\right)$.

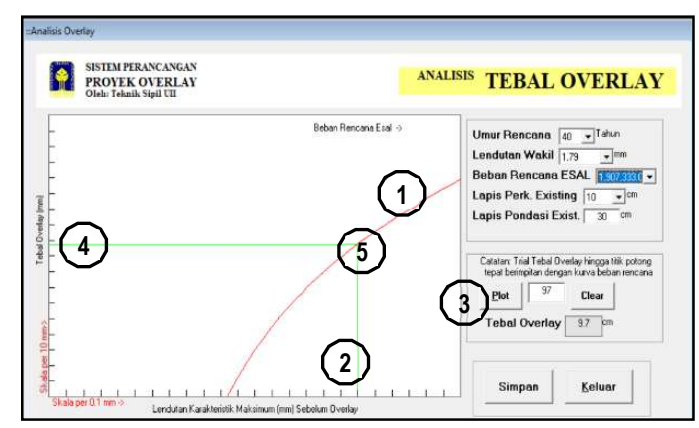

Gambar 7. Menu analisis tebal overlay

Penentuan tebal lapis tambah merupakan tahap berikutnya sebagaimana yang ditunjukkan pada Gambar 7. Pada antarmuka analisis tebal lapis tambahan, pengguna dapat memilih kurva beban rencana yang terdekat dengan hasil perhitungan CESAL. Kurva ini akan muncul pada grafik (langkah 1). Lendutan wakil dan garis vertikal juga akan muncul pada grafik tersebut (langkah 2). Selanjutnya, pengguna dapat melakukan coba-coba (trial and error) tebal lapis dengan cara memasukkan nilai tebal rencana dalam satuan milimeter dan mengeplotkan pada grafik (langkah 3). Tebal yang diplotkan pada skala vertikal akan memunculkan garis horisontal (langkah 4) yang akan berpotongan dengan garis vertikal dari titik lendutan wakil. Tebal lapis tambahan yang sesuai akan diperoleh apabila titik potong ini telah berimpit secara grafis dengan kurva beban rencana yang ditentukan sebelumnya (langkah 5). 


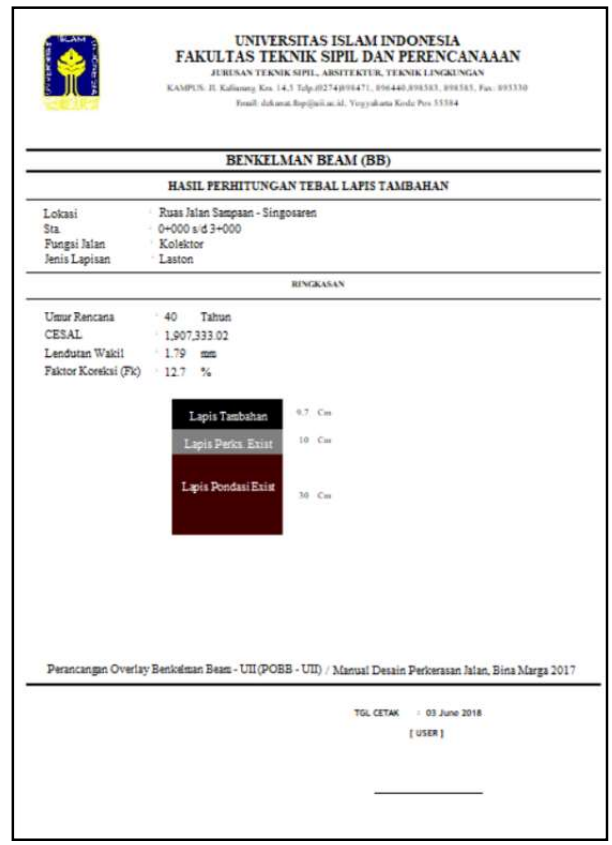

Gambar 8. Tampilan print-out hasil perhitungan

Gambar 8 merupakan hasil perhitungan tebal lapis tambah akan disimpan dalam perangkat lunak dan dapat dicetak menjadi dokumen dengan format PDF.

\section{VALIDASI DAN PEMBAHASAN}

Hasil analisis perhitungan kebutuhan tebal lapis ulang menggunakan perangkat lunak divalidasi dengan melakukan prosedur perhitungan manual sesuai MDPJ Bina Marga
2017. Tiga kasus lapangan tentang desain overlay digunakan untuk melakukan validasi, yaitu: ruas Sampaan - Singosaren, (Susilo, 2018), Kowangan - Maron (Prakoso, 2017) dan Imogiri Barat. Pada kasus desain ruas Sampaan - Singosaren, data pengukuran Benkelman Beam dan data lapangan lainnya diperoleh dari Dinas Pekerjaan Umum, Perumahan, dan Energi Sumber Daya Mineral (PUP-ESDM) Provinsi Daerah Istimewa Yogyakarta. Perbandingan hasil perhitungan perangkat lunak dan manual disajikan pada Tabel 2.

Pada Tabel 2 dapat dilihat bahwa perhitungan analisis beban lalu lintas yang difasilitasi perangkat lunak lebih eksak dan konsisten lebih rendah dibandingkan perhitungan manual. Hal ini dikarenakan pada perangkat lunak digunakan nilai eksaknya, sedangkan pada prosedur perhitungan manual digunakan kurva desain yang terdekat. Pada hasil perhitungan lendutan karakteristik (wakil) tidak terdapat galat yang besar $(<2 \%)$. Pada kasus dengan hasil belum perlu dilakukan overlay, perhitungan berdasarkan perangkat lunak mencapai simpulan hasil akhir yang sama. Pada kasus dengan hasil akhir lapis overlay sangat tipis, perangkat lunak merekomendasikan tebal berselisih 6,25\% dengan rekomendasi perhitungan manual. Namun demikian, secara riil rekomendasi keduanya hanya berselisih $0,1 \mathrm{~mm}$.

Tabel 2. Validasi hasil analisis perangkat lunak

\begin{tabular}{|c|c|c|c|c|c|c|c|c|c|}
\hline \multirow[t]{2}{*}{ Aspek } & \multicolumn{3}{|c|}{$\begin{array}{l}\text { Ruas Kowangan - Maron } \\
\quad \text { (Prakoso, 2017) }\end{array}$} & \multicolumn{3}{|c|}{$\begin{array}{l}\text { Ruas Imogiri Barat } \\
\quad \text { (Susilo, 2018) }\end{array}$} & \multicolumn{3}{|c|}{$\begin{array}{c}\text { Sampaan - Singosaren } \\
\text { (Data sekunder dari Dinas PUP- } \\
\text { ESDM Daerah Istimewa } \\
\text { Yogyakarta) }\end{array}$} \\
\hline & $\begin{array}{l}\text { Perang- } \\
\text { kat } \\
\text { lunak }\end{array}$ & Manual & $\begin{array}{l}\text { Galat } \\
(\%)\end{array}$ & $\begin{array}{l}\text { Perangkat } \\
\text { Lunak }\end{array}$ & Manual & $\begin{array}{c}\text { Galat } \\
(\%)\end{array}$ & $\begin{array}{l}\text { Perangkat } \\
\text { Lunak }\end{array}$ & Manual & $\begin{array}{c}\text { Galat } \\
(\%)\end{array}$ \\
\hline $\begin{array}{l}\text { Beban } \\
\text { Rencana } \\
\text { (CESAL) }\end{array}$ & 266.317 & 300.000 & 11,23 & 875.176 & 900.000 & 2,76 & 1.907 .333 & 2.000 .000 & 4,63 \\
\hline $\begin{array}{l}\text { Lendutan } \\
\text { Wakil } \\
(\mathrm{mm})\end{array}$ & 1,51 & 1,51 & 0,00 & 0,73 & 0,72 & 1,39 & 1,79 & 1,79 & 0,00 \\
\hline $\begin{array}{l}\text { Tebal } \\
\text { overlay } \\
(\mathrm{cm})\end{array}$ & 1,7 & 1,6 & 6,25 & $\begin{array}{l}\text { belum } \\
\text { perlu } \\
\text { overlay }\end{array}$ & $\begin{array}{l}\text { belum } \\
\text { perlu } \\
\text { overlay }\end{array}$ & - & 9,7 & 9,8 & 1,02 \\
\hline
\end{tabular}


Pada kasus beban lalulintas yang terbesar, perhitungan tebal overlay oleh perangkat lunak sangat mendekati perhitungan manual dengan selisih tebal $0,1 \mathrm{~mm} \quad(1,02 \%)$. Memperhatikan perbandingan rekomendasi tebal overlay antara perhitungan manual dan perangkat lunak, dapat disimpulkan bahwa secara mutlak keduanya menghasilkan nilai yang sama secara praktis. Dengan galat di bawah $2 \%$ pada overlay yang cukup tebal untuk beban lalu lintas tinggi, hasil perhitungan perangkat lunak masih dapat diterima validitasnya.

\section{KESIMPULAN DAN SARAN}

Studi ini telah menghasilkan perangkat lunak perancangan tebal lapis tambahan untuk perkerasan lentur dengan metode Benkelman Beam menggunakan Visual Basic 6.0. Prosedur desain dan kurva desain overlay menurut Manual Disain Perkerasan Jalan Bina diimplementasikan dalam perangkat lunak ini. Validasi hasil perhitungan tebal lapis tambahan dengan perangkat lunak menunjukkan perangkat lunak ini cukup akurat untuk digunakan dalam analisis tebal lapis tambahan.

Penelitian selanjutnya dapat dilakukan pada pengembangan algoritma dan fitur optimasi perhitungan tebal lapis ulang sebagai alternatif bagi penggunaan dengan cara trial and error.

\section{UCAPAN TERIMA KASIH}

Penulis mengucapkan terima kasih kepada Dinas PUP-ESDM Daerah Istimewa Yogyakarta atas bantuannya dalam menyediakan data Benkelman Beam ruas Jalan Sampaan-Singosaren yang digunakan untuk keperluan validasi perangkat lunak ini.

\section{DAFTAR PUSTAKA}

Abo-Hashema, M. (2009). “Artificial Neural Network Approach for Overlay Design of Flexible Pavements". The International Arab Journal of Information Technology, Vol. 6, No. 2, April 2009, pp. 204-212.
Badan Standarisasi Nasional. (2011). “Cara Uji Lendutan Perkerasan Lentur Dengan Alat Benkelman Beam”. Jakarta.

Direktorat Jenderal Bina Marga. (2017). "Manual Perkerasan Jalan. Revisi Juni 2017 Nomor 04/SE/Db/2017”. Jakarta.

Gusmalawati, P. (2016). "Pembangunan Perangkat lunak Perencanaan Tebal Lapis Perkerasan Tambahan Metode Benkelman Beam (BB) Menggunakan Aplikasi VBA-Excel”. Tugas Akhir. Universitas Muhammadiyah Yogyakarta.

Prakoso, R. A. (2018). "Evaluasi Kondisi Perkerasan Lentur Dengan Metode PCI Dan Metode Lendutan Balik Untuk Perbaikan". Tugas Akhir. Universitas Islam Indonesia.

Saltan, M., Tigdemir, M., Karasahin, M. (2002). "Artificial Neural Network Application for Flexible Pavement Thickness Modeling”. Computer Journal of Turkish Journal Engineering Environment Science, Vol. 26, No. 1, pp-243-248.

Sarwidi. (2015). "Metode Numerik", Edisi 1. UII Press.

Susilo, P. (2017). "Perencanaan Tebal Lapis Tambah Perkerasan Lentur (Overlay) dengan Metode Lendutan Balik (Studi Kasus: Ruas Jalan Imogiri Barat Kec. Sewon, Kab. Bantul, DIY)". Tugas Akhir. Universitas Muhammadiyah Yogyakarta.

Transportation Research Board of the National Academies. (2004). "Guide for the Mechanistic-Empirical Design of New \& Rehabilitated Pavement Structures". NCHRP Project 1-37A, Washington DC.

WASHO. (1954). "The WASHO Road Test, Part 1 - Design, Construction, and Testing Procedures". HRB Special Report 18. 